\title{
Project Communication Management Patterns
}

\author{
Karolina Muszyńska \\ University of Szczecin, Faculty of Economics and Management \\ ul. Mickiewicza 64, 71-101 Szczecin, Poland \\ tel. +48914441911 \\ e-mail: karolina.muszynska@usz.edu.pl
}

\begin{abstract}
In present, dynamically developing organizations, that often realize business tasks using the project-based approach, effective project management is of paramount importance. Numerous reports and scientific papers present lists of critical success factors in project management, and communication management is usually at the very top of the list. But even though the communication practices are found to be associated with most of the success dimensions, they are not given enough attention and the communication processes and practices formalized in the company's project management methodology are neither followed nor prioritized by project managers. This paper aims at supporting project managers and teams in more effective implementation of best practices in communication management by proposing a set of communication management patterns, which promote a context-problem-solution approach to communication management in projects.
\end{abstract}

\section{INTRODUCTION}

$\mathrm{C}$ OMMUNICATION management is deemed by many as one of the most important knowledge areas in project management and a very complex one at the same time. It is affected by many factors, like characteristics of project stakeholders, project environment, project communication structure, communication properties, physical and psychological barriers [1]. Research has shown that there is a direct connection between communication and a project's outcome, which is determined by the design of the communication environment of the project [2]. Project communication and networking skills are considered to be the life blood of project management leadership [3] and awareness of the potential offered by efficient communication is an essential prerequisite for success in the business world [4].

Project management methodologies, frameworks and sets of principles like Project Management Body of Knowledge, Prince 2, Adaptive Project Framework, Agile Software Development, Scrum, and others, include rules, hints and procedures regarding various communication management aspects, which in most cases should be sufficient to properly manage communication in a project team. The reason why

This publication was financed from the funds of the Faculty of Economics and Management, University of Szczecin. this is not always the case is that, many IT companies do not actually follow any of these methodologies when realizing projects (for example, $30 \%$ of the companies surveyed in [5]) and those that do, tend to concentrate on other project management knowledge areas, which seem more important, like scheduling, cost management, etc. There are also numerous cases of project failures [6], that could be linked to poor communication management (among others [7], [8]).

Thus it seems important to constantly promote good communication management practices and look for new ways to support project managers and team members in better realization of communication and documentation processes in their projects. That is the main goal behind the communication management patterns proposed in this paper - to give project teams an additional tool in a form of a list of patterns for controlling, managing and effective realization of communication and documentation processes. The idea behind patterns is that they provide general, reusable solutions to common problems, and as such are useful for the project team. Communication management patterns described in this paper are based on two main sources of information - communication management best practices identified in subject literature and results of a survey conducted among IT project managers.

The following, second section of the paper, provides evidence on the significance of project communication management knowledge area based on existing literature. In section III, the definition of a pattern is given and some examples of pattern usage are described. The essential fourth section of the paper begins with a definition of the project communication management pattern and on that base subsequent communication management patterns are defined. Conclusions and future research directions end the paper.

\section{SigNIFICANCE OF PROJECT COMMUNICATION MANAGEMENT}

The successful implementation of a project depends on its appropriate management in a number of areas, as described in detail by e.g. Kerzner [9], Schwalbe [10], and Meredith and Mantel [11]. One of the areas of project management identified within numerous methodologies and frameworks is 
communication management, which is considered to be of crucial importance to the success of a project (among others [12], [13]), in particular IT projects [14] especially those carried out by dispersed teams [15], [16], [17], [18], [19]. On the one hand importance of this knowledge area is emphasized by most stakeholders, but on the other hand, the communication processes and practices formalized in the company's project management methodology are neither followed nor prioritized by project managers [20]. For instance, recent research on utilization of project communication management methodologies in industrial enterprises in Slovak Republic revealed that $66 \%$ of the surveyed enterprises had not prepared any written document (methodology, process steps, etc.) to manage project communication [21].

Also Papke-Shields and co-authors, in their research on the use of project management practices and the link thereof to project success, discover that practices related to communication are not given enough attention, while at the same time communication practices are found to be associated with most of the success dimensions [22]. Most of the communication process in a project is usually done without proper planning, driven mostly by personalities and preferences rather than by needs, protocols and procedures [23].

Effective communication techniques and appropriate leadership styles are emphasized by Nguyen as the success factors for building and managing high performance global virtual teams [24]. Communication management is highly influenced in intercultural project teams by such factors as language, race, age, gender, religion, beliefs, habits, etc., whose analysis is essential if the project is to be accomplished with success [25].

According to PMI's Pulse research, 55 percent of project managers agree that effective communication with all stakeholders is the most critical success factor in project management [26]. Effective project communications ensure that the right information reaches the right person at the right time and in a cost-effective manner. Communication is the key to keeping team members, managers, and stakeholders informed and on track to pursue the project objectives, as well as to identifying issues, risks, misunderstandings, and all other challenges to project completion. Effective communication is a critical element of team effectiveness, both in traditional and virtual teams [27] and it is much more than message exchange, rather a way in which project managers generate the grounds for a project [28].

\section{Definitions And The Use Of PATterns}

One of the general definitions of a pattern states that it is "a regular and intelligible form or sequence discernible in the way in which something happens or is done" or "an excellent example for others to follow" [29]. Design patterns are used to represent knowledge that is based on experiences captured in several real world projects and is widely accepted. This representation is often used for describing and presenting the gained knowledge. There are similar concepts to the concept of a pattern - success factor, success models, success measures, reference architectures, best practices, worst practices, barriers, facilitators or incentives [30].

Different definitions for a pattern exist, but they all include a common ground - patterns are general, reusable solutions to common problems and are dependent on their context [31]. They are based on the philosophy of pattern languages, first proposed by architect Christopher Alexander, which is now widely applied in many other professional areas to encompass creative human actions ([32] and works cited therein).

The following subsections describe the structure and format of patterns defined in three knowledge areas - design patterns in software engineering, knowledge management patterns and collaboration patterns. These examples have served as a reference for the structure of communication management patterns defined in the subsequent section.

\section{A. Design Patterns in Software Engineering}

In the software discipline, a pattern describes a problem, which occurs recurrently and supports a solution to that problem in a given context. The pattern has four essential elements: the pattern name, the problem, which describes when to apply the pattern (it explains the actual problem and its context), the solution, which describes the elements that make up the design, their relationships, responsibilities and collaborations (this is an abstract description, a template of a solution), and the consequences - the results and trade-offs of applying the pattern.

To describe each design pattern, a consistent format has been used, including specific sections like: pattern name, intent (explains what the design pattern does, what particular issue/problem it addresses), motivation (a scenario illustrating a design problem and how the pattern solves it), applicability (situations when the design pattern can be applied, examples of poor designs where the pattern could be applied), structure (a graphical representation of classes in the pattern, accompanied with interaction diagrams), participants (classes participating in the design pattern and their responsibilities), collaborations (how the participants collaborate to carry out the responsibilities), consequences (the trade-offs and results of using the pattern), implementation (pitfalls, hints, techniques useful in pattern implementation), sample code, known uses (examples of the pattern found in real systems, related patterns (which patterns are closely related to each other). Each defined design pattern is described according to the above mentioned sections, which makes them easier to use, learn and compare [33].

\section{B. Knowledge Management Patterns}

Knowledge management patterns state lessons learned and best practices for the structuring of knowledge, the design of 
knowledge management systems, and the development of underlying ontologies. Patterns in knowledge management represent also a form of language that helps knowledge engineers to communicate about knowledge and knowledge management systems.

A knowledge pattern is defined as a general, proven, and beneficial solution to a common, reoccurring problem in knowledge design, i.e., the structuring and composition of the knowledge or the ontology defining metadata and potential relationships between knowledge components. Knowledge management patterns are described in seven groups regarding different aspects of knowledge: content, usage, ontology, presentation, transfer, knowledge management systems organization and social knowledge management. Each pattern is described according to a template including the following sections: name, issue (problem addressed by the pattern), q-effect (what knowledge quality aspects are affected by the pattern and if it is a positive, negative or neutral effect), solution (principal solutions underlining the pattern), causes (basic causes of the pattern) [30].

\section{Collaboration Patterns}

Collaboration patterns strive to verbalize tips on achieving teamwork that creates new values. They are used to help teams achieve creative collaboration through their interactions and discover methods to engage in effective teamwork.

Each collaboration pattern comprises of two main parts the first one, giving a brief idea of the pattern, including the following elements: name, one-liner (short description of the pattern), illustration and quotes related to the pattern, and the second part, offering more details, with the following sections: context, problem, forces, solution, actions and consequences, which describe how things can change when a certain pattern is applied [34].

There are also other views on collaboration patterns, like the Schadewitz's design patterns for cross-cultural collaboration [35].

According to the classification proposed by Verginadis et al. [36], the project communication management patterns, specified in the subsequent section, could be considered as a specific kind of patterns in collaborative work, and precisely classified as "an approach that aims to directly assist participants", and "which requires manual intervention".

\section{Project Communication Management Patterns}

\section{A. Definition of a Project Communication Management Pattern}

The definition of the project communication management pattern proposed in this subsection is a result of the analysis of patterns and their frameworks developed in different disciplines, and combining selected aspects of these patterns with project communication management characteristics and practices.

Project communication patterns have been grouped into four categories according to the communication management practice categories described in [37] - informational (regarding generation, collection, dissemination, storage, and disposition of project information), strategic (connected with communication planning and project environment), emotional (concerning the building of trust and relationships) and practical (connected with clear and positive communication and behavior rules). Within each category, several communication management patterns were defined. Each pattern comprises of the following sections: pattern name, context, problem, solution, q-effect (what communication quality aspects are affected by the pattern and if it is a positive or a negative influence), applicability (situations, teams and projects where the communication management pattern should be applied), participants (parties participating in the communication/documentation process and their responsibilities), consequences (the trade-offs and results of using the pattern), implementation (pitfalls, hints, techniques useful in the pattern implementation), and related patterns.

For specifying q-effect the following communication quality aspects were considered: clearness and cohesion, adequate level of detail, right time, meeting needs of communicating participants, engaging right people, guarantee of uniform understanding of the content, communication workflow supporting openness, redundancy and feedback.

Solution within a pattern describes what actions should be undertaken to realize the pattern and the communication management goal that it supports.

The project communication management patterns described in the subsequent subsections are based on two main sources of knowledge. The first source are communication management best practices described in literature [38]-[43], [16] and thoroughly discussed in [37], and the second source are the opinions gained from practitioners (mostly project managers realizing IT projects) from 10 national and international IT companies operating in Poland. A structured interview with both closed and openended questions was used to obtain their opinions.

\section{B. Informational Communication Management Patterns}

Within the informational category, three communication management patterns have been specified: Communication schedule, Project knowledge center and Diversity of communication means. According to the survey, carried out among practitioners, all the following patterns are known to almost all of them and used in their companies. In one case it has been stated that the Communication schedule pattern is an intrinsic element of the communication plan, which is prepared at the start of the project realization. 
Table I provides characteristics of the three project communication management patterns from the informational category, developed according to the defined template.

For the sake of brevity the pattern section names were abbreviated as follows: $\mathrm{Cx}$ (context), $\operatorname{Pr}$ (problem), S (solution), Q (q-effect), A (applicability), P (participants), $\mathrm{Cq}$ (consequences), I (implementation) and RP (related patterns).

TABLE I.

COMMUNICATION MANAGEMENT PATTERNS WITHIN THE INFORMATIONAL CATEGORY

\begin{tabular}{|c|c|}
\hline \multicolumn{2}{|c|}{ Communication schedule } \\
\hline $\mathrm{Cx}$ & $\begin{array}{l}\text { The project team is dispersed, some team members are in different time zones; according to the project communication plan project partners } \\
\text { should inform each other of the project status to get feedback and encourage involvement. }\end{array}$ \\
\hline $\operatorname{Pr}$ & $\begin{array}{l}\text { Communication between team members is too scarce, team members limit communication to sending reports, while direct communication } \\
\text { takes place only in emergency situations. }\end{array}$ \\
\hline $\mathrm{S}$ & $\begin{array}{l}\text { Prepare a communication time schedule, including bilateral communication between particular team members, as well as multilateral } \\
\text { audio/video conferences among wider forum of team members; communication participants possibilities and preferences concerning } \\
\text { communication medium and time zone shifts should be taken into account. }\end{array}$ \\
\hline $\mathrm{Q}$ & $\begin{array}{l}\text { Positive on the following communication quality aspects: up to date information on the project tasks status; redundancy, feedback. Negative } \\
\text { on the following communication quality aspects: in case of multilateral audio/video conferences too many participants taking part may cause } \\
\text { the communication to be ineffective and irritating (technical problems are more likely to appear) and not engaging the right people. }\end{array}$ \\
\hline A & $\begin{array}{l}\text { The pattern can be used for any kind of project and team, although it is especially useful for dispersed teams and bigger projects longer than } \\
\text { three months. }\end{array}$ \\
\hline $\mathrm{P}$ & $\begin{array}{l}\text { Any team member that is included in the communication time schedule; team members are responsible for adhering to the time schedule or } \\
\text { timely informing about any derogations; a very important issue in realizing this pattern is engaging only the concerned team members in } \\
\text { multilateral conferences (thematic groups). }\end{array}$ \\
\hline $\mathrm{Cq}$ & $\begin{array}{l}\text { Ensures regular communication among team members, adjusted to their working day schedules and communication preferences, and keeps } \\
\text { everybody informed about the status of project tasks and encourages instant feedback. }\end{array}$ \\
\hline I & $\begin{array}{l}\text { Setting up a communication time schedule requires time, effort, cooperation and goodwill of team members, so that it is adhered to and } \\
\text { beneficial; the more parties and localizations the more difficult it becomes; it should be agreed upon during the project kick-off meeting, } \\
\text { accompanied by a clear message of its goal and instructions of realization; using such tools as shared calendars and communication matrix } \\
\text { can be useful. }\end{array}$ \\
\hline $\mathrm{RP}$ & Clear rules at the start \\
\hline \multicolumn{2}{|c|}{ Project knowledge center } \\
\hline $\mathrm{Cx}$ & $\begin{array}{l}\text { Communication in the project team is performed in different ways; many people use e-mail as the primary communication medium, and send } \\
\text { various elements of the project documentation this way. Others prefer communication via Instant Messaging (IM) and attaching files to } \\
\text { conversations. Still others would rather talk on the phone and deliver files on a pen drive. }\end{array}$ \\
\hline $\operatorname{Pr}$ & $\begin{array}{l}\text { Many elements of the project documentation remain only in mail boxes/computers/pen-drives of individual team members and project } \\
\text { knowledge in their heads; different versions of the same documents are created and their subsequent synchronization is very cumbersome; } \\
\text { some information is lost or finding it is time-consuming; certain project knowledge is lost when a team member leaves the team. }\end{array}$ \\
\hline $\mathrm{S}$ & $\begin{array}{l}\text { Ensuring a project repository - project knowledge center, where project files are placed, stored and shared; a web portal with a wiki feature, } \\
\text { group-work tool or project management software with the file versioning and change tracking functionalities can be used for that purpose; to } \\
\text { wean team members from sending project documents as attachments to e-mails, a special function could be embedded in the e-mail program, } \\
\text { which would display a message asking the user if the attached file should not rather be placed in the repository, instead of being sent. }\end{array}$ \\
\hline Q & $\begin{array}{l}\text { Positive on the following communication quality aspects: clearness and cohesion, up-to-date project documentation, adequate level of detail } \\
\text { and communication workflow supporting openness. Negative on the following communication quality aspects: in case the repository is } \\
\text { unordered and unclear the adequate level of detail, clearness and cohesion are no longer attained. }\end{array}$ \\
\hline A & $\begin{array}{l}\text { The pattern should be used for any kind of project and team, because even small projects and small teams produce project documentation } \\
\text { which should be made available to the team and the cumulated knowledge may prove useful in future projects. }\end{array}$ \\
\hline $\mathrm{P}$ & $\begin{array}{l}\text { All team members producing any kind of project documentation or content; team members are responsible for uploading any project-related } \\
\text { documentation in an orderly manner, established upfront or developed in the initial phase of the project realization. }\end{array}$ \\
\hline $\mathrm{Cq}$ & $\begin{array}{l}\text { Ensures a common project documentation reference center available to all team members, taking into account given user access rights, with } \\
\text { up-to-date project documentation and orderly history. Project documentation is not hidden in the mail boxes of individual team members and } \\
\text { a project knowledge base is being built. Team members do not have to communicate or send specific information separately to all interested } \\
\text { parties but just link them to the appropriate place in the project knowledge center. }\end{array}$ \\
\hline I & $\begin{array}{l}\text { Setting up a project knowledge center requires using appropriate tools and setting certain procedures, so that the repository is easy to use and } \\
\text { is effective in storing and sharing information; it is usually a software application chosen and used by the project team for many projects. } \\
\text { Problems which may arise concern effective organization of the repository and a need for training team members how to use versioning tools. } \\
\text { The chosen tool usually requires configuration effort and expertise and some systems are expensive. Sometimes documents sharing between } \\
\text { the customer and the developer is not at all possible due to security issues. }\end{array}$ \\
\hline $\mathrm{RP}$ & - \\
\hline
\end{tabular}




\begin{tabular}{|c|c|}
\hline \multicolumn{2}{|c|}{ Diversity of communication means } \\
\hline $\mathrm{Cx}$ & $\begin{array}{l}\text { It happens that tools used in the project team impose the way of communication among team members, limiting it mainly to written } \\
\text { communication (e.g. to have a permanent evidence of discussions and arrangements). Team members hardly talk to each other personally; this } \\
\text { is particularly common in the case of international and distributed teams. }\end{array}$ \\
\hline $\operatorname{Pr}$ & $\begin{array}{l}\text { Focusing mainly on one way of communication, whether oral or written, hampers the implementation of the project, in the first case because } \\
\text { of the transience of oral arrangements, in the second case, because of possible problems with understanding the intentions or the lack of } \\
\text { instant response. In the case of written real time communication (using IM) the typing speed can be a problem, while for oral communication } \\
\text { a poor knowledge of a foreign language can be a barrier. }\end{array}$ \\
\hline $\mathrm{S}$ & $\begin{array}{l}\text { The solution to the problems associated with using mainly one communication means is to promote diversity in the ways of communication, } \\
\text { and while preserving the principles of the Project knowledge center pattern, emphasize the importance of oral communication, which should } \\
\text { support mutual understanding between team members and unite the project team. }\end{array}$ \\
\hline Q & $\begin{array}{l}\text { Positive on the following communication quality aspects: meeting needs of communicating participants (as some team members are } \\
\text { comfortable with written communication, while others need to communicate also orally), guarantee of uniform understanding of the content, } \\
\text { redundancy and instant feedback (in case of oral communication). Negative on the following communication quality aspects: in case of } \\
\text { excessive diversity, project documentation consistency and cohesion is hard to maintain. }\end{array}$ \\
\hline A & $\begin{array}{l}\text { The pattern should be used carefully, taking into account the communication culture of the project team, level of project language knowledge } \\
\text { of team members and security issues (some communication tools may be considered as not secure). }\end{array}$ \\
\hline$P$ & $\begin{array}{l}\text { All team members, and especially the project manager should take into account personal predispositions of each member to avoid forcing } \\
\text { them to use communication means which they are not comfortable with. }\end{array}$ \\
\hline $\mathrm{Cq}$ & $\begin{array}{l}\text { Diversity of communication, on the one hand enriches and facilitates communication among team members, but on the other hand, if not } \\
\text { appropriately managed, may cause communication chaos, with some information being lost in oral conversations or time wasted during too } \\
\text { frequent and ineffective meetings. }\end{array}$ \\
\hline I & $\begin{array}{l}\text { The written form of communication, especially the part concerning communicating project results and producing project documentation, } \\
\text { should be arranged at the beginning and organized into effective and easy to understand and follow procedures, which should be realized by } \\
\text { all team members (see Clear rules at the start pattern). One of the most effective oral communication means are stand-up meetings, known } \\
\text { from the agile project management approach, which are a quick and effective way to find out what is the status of project tasks, who needs } \\
\text { help, or who is not working properly. It is also a perfect way for team members to get to know each other. It is however important that the } \\
\text { project manager, or leader does not dominate these meetings. In case of dispersed teams video-conference stand-up meetings can be } \\
\text { organized. In case of traditional meetings their costs (time, travel) must be taken into account and planned in advance. }\end{array}$ \\
\hline $\mathrm{RP}$ & Clear rules at the start, Project knowledge center \\
\hline
\end{tabular}

\section{Strategic Communication Management Patterns}

Another three communication management patterns have been defined within the strategic category: Clear rules at the start, Cultural and language competencies and Client's power scope. These patterns were also acknowledged and used by most of the surveyed practitioners, although Cultural and language competencies pattern was not used by more than one third of them because their project teams were not culturally or linguistically diverse. Others argued that both
Clear rules at the start, as well as Client's power scope, are part of the communication plan and need not to be separately described, but that is the role of patterns to highlight specific problematic areas to which solutions are proposed - in the case of Clear rules at the start pattern, preparing a highquality communication plan is actually the suggested solution.

Table II provides an overview of the three project communication management patterns from the strategic communication management practice category.

TABLE II.

COMMUNICATION MANAGEMENT PATTERNS WITHIN THE STRATEGIC CATEGORY

\begin{tabular}{|c|l|}
\hline \multicolumn{2}{|c|}{ Clear rules at the start } \\
\hline $\mathrm{Cx}$ & $\begin{array}{l}\text { It sometimes happens that while planning various aspects of the project (project tasks, responsible team members, schedule and budget), the } \\
\text { area of communication and documentation management is neglected. There is no regular contact with the client to inform them about the } \\
\text { progress of the project and for keeping in touch for quick reaction to possible changes and new requirements. If there are no assigned tasks and } \\
\text { people associated with the management and implementation of communication, nobody will take care of it. }\end{array}$ \\
\hline $\mathrm{Pr}$ & $\begin{array}{l}\text { There are no designated persons and tasks related to planning and managing communication and documentation processes. Team members feel } \\
\text { no need to communicate the status of their tasks, nor do they feel responsible for informing the client about the status of the project. }\end{array}$ \\
\hline $\mathrm{S}$ & $\begin{array}{l}\text { Development of a clear, practical and high-quality communication plan with assigned persons responsible for communication management, } \\
\text { description of communication and documentation tasks - the ones to be carried out by specific individuals and those which are the } \\
\text { responsibility of all members of the project team. In the case of distributed teams, it is particularly important to include the Communication } \\
\text { schedule pattern. In the case of various language speaking teams, a common project communication language should be established. }\end{array}$ \\
\hline $\mathrm{Q}$ & $\begin{array}{l}\text { Positive on the following communication quality aspects: meeting needs of communicating participants. Negative on the following } \\
\text { communication quality aspects: in case of excessive formalism and bureaucracy participants may be discouraged to communicate effectively. }\end{array}$ \\
\hline $\mathrm{A}$ & $\begin{array}{l}\text { The pattern should be used for any kind of project and team, although it is especially useful for teams with different working cultures and fixed } \\
\text { price projects. }\end{array}$ \\
\hline
\end{tabular}




\begin{tabular}{|c|c|}
\hline $\mathrm{P}$ & $\begin{array}{l}\text { Every project stakeholder should be included in the communication plan. All persons assigned to any communication and documentation tasks } \\
\text { should be clearly informed of their responsibilities at the beginning of the project realization. }\end{array}$ \\
\hline $\mathrm{Cq}$ & $\begin{array}{l}\text { Ensures that all team members and project stakeholders know their communication and documentation responsibilities. Client is instantly } \\
\text { informed about the status of the project tasks. It is, however, important to let the communication plan evolve and alter throughout the project, } \\
\text { to make it better tailored to the given project and team. }\end{array}$ \\
\hline I & $\begin{array}{l}\text { Preparing a high-quality communication plan requires time and effort, so that it is then easy to realize and not burdensome for the project team; } \\
\text { too much formalism may discourage the team; the communication plan should be communicated already during the project kick-off meeting, } \\
\text { or at least during the initiation phase of the project. }\end{array}$ \\
\hline RP & Communication schedule \\
\hline \multicolumn{2}{|c|}{ Cultural and language competencies } \\
\hline $\mathrm{Cx}$ & $\begin{array}{l}\text { In the case of multicultural teams or teams whose members come from different language areas, difficulties in communication, due to problems } \\
\text { with mutual understanding, may appear. This situation may affect the members of one team or members of two collaborating teams (the } \\
\text { client's side team and the developer's side team). }\end{array}$ \\
\hline $\operatorname{Pr}$ & $\begin{array}{l}\text { Problem with the lack of cultural and/or language competence of team members, which hinders communication and mutual understanding, and } \\
\text { thereby successful realization of the project. }\end{array}$ \\
\hline $\mathrm{S}$ & $\begin{array}{l}\text { Team members should be prepared for the environment in which they are going to work and familiarized with the rules and customs prevailing } \\
\text { in the country of other team members. Necessary language skills should also be checked to ensure comfortable communication. }\end{array}$ \\
\hline Q & $\begin{array}{l}\text { Positive on the following communication quality aspects: clearness and cohesion, meeting needs of communicating participants, guarantee of } \\
\text { uniform understanding of the content. }\end{array}$ \\
\hline A & The pattern is suitable for teams working in multicultural and international projects. \\
\hline $\mathrm{P}$ & All team members engaged in an international/multicultural project, who are responsible for communication and documentation tasks. \\
\hline $\mathrm{Cq}$ & Culturally and linguistically competent team members facilitate communication and make the internal cooperation easier and more efficient. \\
\hline I & $\begin{array}{l}\text { Having culturally and linguistically competent team members is not always possible or easy to achieve. Learning a foreign language is a long } \\
\text { process and getting to know different culture is difficult. If there is at least one competent person in the project team they can train the team. It } \\
\text { is also a good idea to promote and use "project culture", which is above local cultures of particular team members. In case of language } \\
\text { problems in written communication, such tools as online translators or spell-checkers can be used. For oral communication a linking-person, } \\
\text { who can freely communicate with both parties, is a solution. }\end{array}$ \\
\hline RP & - \\
\hline \multicolumn{2}{|c|}{ Client's power scope } \\
\hline $\mathrm{Cx}$ & $\begin{array}{l}\text { A strategic issue in project implementation is to clarify the scope of power on the client's side. This is particularly necessary in case of } \\
\text { problems with precise determination of requirements or their frequent changes. In order to ensure smooth communication between the project } \\
\text { team and the client's team, it is important to establish the competence scope. }\end{array}$ \\
\hline $\operatorname{Pr}$ & $\begin{array}{l}\text { The project team does not know who, on the client's side, is responsible for making and communicating decisions concerning the project, as } \\
\text { well as who to contact in problematic issues. }\end{array}$ \\
\hline S & $\begin{array}{l}\text { Project manager must ensure that the client has appointed a person or persons who will be responsible on the client's side for making and } \\
\text { communicating decisions throughout the project, and who should be contacted in problematic issues. }\end{array}$ \\
\hline Q & $\begin{array}{l}\text { Positive on the following communication quality aspects: clearness and cohesion, engaging the right people, communication workflow } \\
\text { supporting openness. }\end{array}$ \\
\hline A & The pattern is applicable to any team and project, because clear definition of responsibility for making decisions is always desirable. \\
\hline $\mathrm{P}$ & All team members, project manager, client's team. \\
\hline $\mathrm{Cq}$ & $\begin{array}{l}\text { Clearly defined responsibility for certain competence areas. Clear decision-making procedure. Clearly defined deadlines for document } \\
\text { verification and approval. Effective problem reporting. }\end{array}$ \\
\hline I & $\begin{array}{l}\text { Client's power scope should be defined at the very beginning of the project realization (communication aspects should be included in the } \\
\text { communication plan - Clear rules at the start pattern). It is however important to be flexible and ready for negotiations of responsibilities and } \\
\text { authorities. It is a good practice to assign representatives on both sides - mutual counterparts. Using the same standards for communication or } \\
\text { process templates can also be helpful. Problems in implementing the pattern may arise in the case of dominant position of the client and } \\
\text { reluctance to compromise, fear of making decisions, not properly chosen/prepared team on the client's side, conflicts within the client's team. }\end{array}$ \\
\hline RP & Clear rules at the start \\
\hline
\end{tabular}

\section{Emotional Communication Management Patterns}

The emotional category of communication management practices comprises of another three patterns: Fostering direct communication, Visits and team rotations and Appreciating the team. Most of the practitioners, who were surveyed, knew all three patterns and used them in their project teams. One of them was however very sceptic towards the Fostering direct communication pattern, claiming that the pattern should actually be quite the contrary, because people tend to waste a lot of time on unproductive and ineffective talks and meetings.

The above mentioned patterns from the emotional communication management practice category are described in table III. 
TABLE III

COMMUNICATION MANAGEMENT PATTERNS WITHIN THE EMOTIONAL CATEGORY

\begin{tabular}{|c|c|}
\hline \multicolumn{2}{|c|}{ Fostering direct communication } \\
\hline $\mathrm{Cx}$ & $\begin{array}{l}\text { Absorbed in work and rushed by deadlines, project team members often do not have time for direct talks with each other or with team } \\
\text { members on the client's side. It also happens that the management restricts such direct contacts (chats in the hallway or through IM), treating } \\
\text { it as a waste of time and delaying tasks. }\end{array}$ \\
\hline $\operatorname{Pr}$ & $\begin{array}{l}\text { Team members are alienated and feel discomfort associated with inability to satisfy human needs, these associated with direct contact with } \\
\text { another person. Such reduction of direct communication restrains the team from uniting, understanding each other's needs and hinders } \\
\text { comprehension. }\end{array}$ \\
\hline S & $\begin{array}{l}\text { Project manager should promote direct communication between team members, as well as with members of the team on the client's side. This } \\
\text { may be achieved in various ways, through the use of Communication schedule pattern that takes into account the direct methods of } \\
\text { communication (in the case of distributed teams, at least audio- or videoconferencing), through the use of social networking tools ("virtual } \\
\text { water cooler"), where team members could talk informally, and through regular project meetings (stand-up meetings, reviews). }\end{array}$ \\
\hline Q & $\begin{array}{l}\text { Positive on the following communication quality aspects: meeting needs of communicating participants, guarantee of uniform understanding } \\
\text { of the content, communication workflow supporting openness, redundancy, feedback. }\end{array}$ \\
\hline A & $\begin{array}{l}\text { The pattern should be used for any kind of project and team, although in the case of distributed teams "direct" usually means audio or } \\
\text { videoconferences, as face-to-face meetings are costly and time-consuming. }\end{array}$ \\
\hline $\mathrm{P}$ & $\begin{array}{l}\text { All project team members should be able to take advantage of this pattern, although project manager should track the impact of direct } \\
\text { communication on project performance. }\end{array}$ \\
\hline $\mathrm{Cq}$ & $\begin{array}{l}\text { May prove very beneficial to the project and the team if properly used; both formal and informal direct communication fosters better mutual } \\
\text { understanding, team uniting, issues resolving. It must be however properly managed and monitored to prevent team members from wasting too } \\
\text { much time and delaying realization of tasks - this mainly concerns poorly prepared meetings. }\end{array}$ \\
\hline I & $\begin{array}{l}\text { As far as formal communication is concerned, stand-up meetings can bring much profit, because they convey both information and emotions } \\
\text { and let the team get to know each other better. Informal communication can be supported by social networking tools, informal chat-rooms or a } \\
\text { common meeting room (in case of local teams). Use of the Visits and team rotations pattern is also a method of fostering direct } \\
\text { communication and letting different team members get to know each other. Access to direct communication should also be made easy by } \\
\text { supporting a list of team members' phone numbers, IM contact details, etc. }\end{array}$ \\
\hline $\mathrm{RP}$ & Communication schedule, Visits and team rotations, Diversity of communication means \\
\hline \multicolumn{2}{|c|}{ Visits and team rotations } \\
\hline $\mathrm{Cx}$ & $\begin{array}{l}\text { A very important aspect in project realization is the mutual trust and understanding of team members. If the direct contact of the contractor's } \\
\text { team with the client's team is limited to the kick-off meeting and a few other project meetings, then it is hard to achieve. }\end{array}$ \\
\hline $\operatorname{Pr}$ & Lack of trust and willingness to communicate within the project team, because of the lack of direct contact and familiarity of team members. \\
\hline S & $\begin{array}{l}\text { A possible way to solve this problem are regular visits of individual team members at the client's/contractor's site, as well as delegating a team } \\
\text { member to the client's/contractor's site to facilitate communication. In the latter solution, rotation can also be used, so that different team } \\
\text { members can get to know each other, and thus break the communication barrier. }\end{array}$ \\
\hline Q & $\begin{array}{l}\text { Positive on the following communication quality aspects: meeting needs of communicating participants, communication workflow supporting } \\
\text { openness, feedback. }\end{array}$ \\
\hline A & $\begin{array}{l}\text { The pattern is suitable for certain projects and environments, because usually a single team member has too scarce knowledge of the project } \\
\text { and sending the whole team is neither possible nor effective; beneficial mostly in big projects with distributed teams. }\end{array}$ \\
\hline $\mathrm{P}$ & $\begin{array}{l}\text { Only willing team members should be chosen for delegation to other locations, to avoid discontent and frustration experienced by people } \\
\text { forced to leave their home city and family for a longer period of time. Shorter visits should be realized by all key team members. }\end{array}$ \\
\hline $\mathrm{Cq}$ & $\begin{array}{l}\text { Building non-professional relations among team members fosters effective and direct communication (relation with Fostering direct } \\
\text { communication pattern). Delegated team members facilitate communication between the client's team and the contractor's team. }\end{array}$ \\
\hline I & $\begin{array}{l}\text { Realization of the pattern should be preceded by an analysis of predispositions and willingness of individual team members to delegations, so } \\
\text { that appropriate plan of visits and team rotation can be developed and included in the budget. In reasonable circumstances bonuses or family } \\
\text { delegations can be offered. }\end{array}$ \\
\hline RP & Fostering direct communication \\
\hline \multicolumn{2}{|c|}{ Appreciating the team } \\
\hline $\mathrm{Cx}$ & $\begin{array}{l}\text { In the course of project realization team members notice errors or possibilities for better solutions to various problems. However they do not } \\
\text { always have the opportunity to express their views, to give advice or share opinions, or they do not know how and where it can be done. With } \\
\text { some team members this may cause frustration and decrease motivation, others may not care about it, but the failure to take their opinions into } \\
\text { account may prove to be unfavorable for the project. }\end{array}$ \\
\hline $\operatorname{Pr}$ & $\begin{array}{l}\text { The project management does not enable team members to share opinions, to formulate proposals or comments related to the implementation } \\
\text { of the project. They cannot express their feelings, thoughts and remarks, and feel unappreciated and their motivation to work decreases. }\end{array}$ \\
\hline S & $\begin{array}{l}\text { Encouraging team members to share their thoughts, remarks and opinions. This can be achieved, inter alia, by reserving a project portal } \\
\text { section for this purpose. This section can also be used by the project management to formulate requests for support and advice, which would } \\
\text { give the team a sense of appreciation of their value and trust. }\end{array}$ \\
\hline Q & $\begin{array}{l}\text { Positive on the following communication quality aspects: meeting needs of communicating participants, communication workflow supporting } \\
\text { openness, feedback. }\end{array}$ \\
\hline
\end{tabular}




\begin{tabular}{|c|l|}
\hline A & $\begin{array}{l}\text { The pattern is applicable to any team and project, because every team member should have an opportunity to share their thoughts and } \\
\text { opinions and all team members need to feel appreciated. It is especially beneficial in long-term projects where constant improvement of work } \\
\text { quality should take place. }\end{array}$ \\
\hline $\mathrm{P}$ & All team members should have the opportunity to take advantage of this pattern. Project manager should be open to remarks from the team. \\
\hline $\mathrm{Cq}$ & $\begin{array}{l}\text { Appreciated project team is motivated to work towards successful realization of the project; useful remarks and suggestions are collected and } \\
\text { may be applied to foster better project development; alarming situations are exposed and appropriate actions can be undertaken. }\end{array}$ \\
\hline $\mathrm{I}$ & $\begin{array}{l}\text { The pattern may be realized in many different ways - devoting time during project meetings for team opinions, remarks, suggestions; } \\
\text { reserving a project portal section for this purpose or a thematic mailbox; organizing surveys, retrospection sessions. This pattern is connected } \\
\text { with Clear rules at the start, Communication schedule and Fostering direct communication patterns, because all of them strive for letting } \\
\text { team members communicate what they want, need or should communicate in a way which is the most suitable for them. The effort of } \\
\text { organizing and analyzing surveys, mailboxes, retrospection sessions or portal sections should be included in the budget and schedule plan, to } \\
\text { avoid situation that all information is collected in vain. }\end{array}$ \\
\hline RP & \begin{tabular}{l} 
Clear rules at the start, Communication schedule, Fostering direct communication \\
\hline
\end{tabular}
\end{tabular}

\section{E. Practical Communication Management Patterns}

Within the last, practical category, two more communication management patterns have been identified: Basic communication principles and Synchronous working environments. Only one of the surveyed practitioners has not heard about or used the first pattern, while the second one was recognized by all, but not used by more than one third, as it was deemed suitable mainly for big projects.

In table IV the two remaining patterns from the practical communication management practice category have been depicted.

TABLE IV.

COMMUNICATION MANAGEMENT PATTERNS WITHIN THE PRACTICAL CATEGORY

\begin{tabular}{|c|c|}
\hline \multicolumn{2}{|c|}{ Basic communication principles } \\
\hline $\mathrm{Cx}$ & $\begin{array}{l}\text { This pattern applies to the basic principles, which should be observed by all project team members, and of which they should be aware in } \\
\text { order to maintain transparency and positive nature of communication. }\end{array}$ \\
\hline $\operatorname{Pr}$ & Misunderstandings, hostility or animosity among team members. \\
\hline $\mathrm{S}$ & $\begin{array}{l}\text { Reminding team members about the basic principles of transparent, effective and positive communication, and desired behavior, that is, } \\
\text { among others: justifying requests, asking rather than telling, keeping promises and showing up for appointments (also virtual ones), writing } \\
\text { positive emails (even criticisms and dissatisfaction can be expressed in a positive way); it is also a good practice to set the maximum time for } \\
\text { response to an email, to ensure the dynamics of asynchronous communication. }\end{array}$ \\
\hline Q & Positive on the following communication quality aspects: clearness and cohesion, meeting needs of communicating participants. \\
\hline A & $\begin{array}{l}\text { The pattern can be used for any kind of project and team, although it is especially useful for immature and inexperienced teams, or where } \\
\text { there are many introverts, team members are age or culture diversified. }\end{array}$ \\
\hline $\mathrm{P}$ & $\begin{array}{l}\text { All project team members should communicate obeying the rules presented in this pattern, although for some of them, especially the } \\
\text { experienced and mature ones, they may seem obvious. }\end{array}$ \\
\hline $\mathrm{Cq}$ & $\begin{array}{l}\text { Good atmosphere in the team, clear and positive relations among team members and their responsible behavior - all promoting successful } \\
\text { project completion. }\end{array}$ \\
\hline I & $\begin{array}{l}\text { Usually the basic principles of transparent, effective and positive communication is something that every person knows and feels, and it } \\
\text { should not be required to state it explicitly, but in the cases mentioned above it may be desired to bring them to the attention of some team } \\
\text { members. If possible communication rules should be agreed upon together by the whole team, preferably during the kick-off meeting. }\end{array}$ \\
\hline RP & - \\
\hline \multicolumn{2}{|c|}{ Synchronous working environments } \\
\hline $\mathrm{Cx}$ & $\begin{array}{l}\text { In certain environments and usually big projects, it is desirable to have similar project setup and roles for better and easier synchronization of } \\
\text { communication and work. }\end{array}$ \\
\hline $\operatorname{Pr}$ & $\begin{array}{l}\text { Cooperating teams in different locations greatly differ from each other both in terms of composition and way of working, making it difficult } \\
\text { for communication and cooperation between them. }\end{array}$ \\
\hline $\mathrm{S}$ & Provide a similar composition of the teams and work procedures in all locations in order to facilitate cooperation and communication. \\
\hline Q & Positive on the following communication quality aspects: engaging the right people. \\
\hline A & This pattern applies to big and long-term projects carried out by two teams in different locations - the client's and the contractor's team. \\
\hline $\mathrm{P}$ & Team members playing similar roles in both teams. \\
\hline $\mathrm{Cq}$ & $\begin{array}{l}\text { Synchronized working environments on the client's and contractor's side, with defined roles and responsibilities; easier direct communication } \\
\text { due to existence of counterparts. }\end{array}$ \\
\hline I & $\begin{array}{l}\text { Defining a process with roles definition, responsibilities, authorities and templates could be used to set up the synchronous working } \\
\text { environments of the cooperating teams. }\end{array}$ \\
\hline $\mathrm{RP}$ & - \\
\hline
\end{tabular}




\section{CONCLUSION}

The eleven project communication management patterns presented in this paper aim at supporting project managers and teams in effective implementation of communication management practices based on a context-problem-solution approach. The four groups they are arranged into address various aspects of project management and types of encountered problems.

There are at least two main future research directions that can enrich the body of knowledge on project communication patterns. The first is to assess implementation conditions, dependencies and effectiveness of the patterns specified in this paper. The second is to look for and identify more common project communication patterns. Both require conducting a more extensive survey among project-based companies.

\section{ACKNOWLEDGMENT}

Special thanks to all the professionals from the project management field who devoted their precious time to share their experiences, knowledge and opinions on the topic of communication management patterns in project teams in their companies.

\section{REFERENCES}

[1] V. Damasiotis, P. Fitsilis, and J. F. O'Kane, "Measuring communication complexity in projects," in Proceedings of the Management of International Business and Economic Systems (MIBES-ESDO) 2012 International Conference. Larissa, Greece: School of Management and Economics, 2012, pp. 100-114.

[2] M. M. Phillips, Reinventing communication: How to design, lead and manage high performing projects. Farnham, UK: Gower Publishing, Ltd., 2014.

[3] R. Burke, and S. Barron, Project management leadership: building creative teams. Chichester, UK: John Wiley \& Sons, 2014.

[4] M. Charles, "The Ascent of Communication: Are We on Board?," in The Ascent of International Business Communication, L. LouhialaSalminen, A. Kankaanranta, Eds. Helsinki, Finland: Helsinki School of Economics, 2009, pp. 9-23.

[5] K. Muszyńska. "Kształtowanie modelu komunikacji w zespole projektowym," Ph.D. dissertation, University of Szczecin, 2010.

[6] W. Al-Ahmad, K. Al-Fagih, K. Khanfar, K. Alsamara, S. Abuleil, and H. Abu-Salem, "A Taxonomy of an IT Project Failure: Root Causes," International Management Review, vol. 5, no. 1, pp. 93-104, 2009.

[7] K. Conboy, "Project failure en masse: a study of loose budgetary control in ISD projects," European Journal of Information Systems, vol. 19, no. 3, pp. 273-287, 2010. DOI= http://dx.doi.org/ 10.1057/ejis.2010.7.

[8] R. Stoica, and P. Brouse, "IT project Failure: A proposed four-phased adaptive multi-method approach," Procedia Computer Science, vol. 16 , pp. 728-736, 2013. DOI= http://dx.doi.org/10.1016/ j.procs.2013.01.076.

[9] H. R. Kerzner, Project management: a systems approach to planning, scheduling, and controlling. Hoboken, NJ: John Wiley \& Sons, 2013.

[10] K. Schwalbe, Information technology project management. Boston, MA: Cengage Learning, 2013.

[11] J. R. Meredith, and S. J. Mantel Jr., Project management: a managerial approach. Hoboken, NJ: John Wiley \& Sons, 2011.

[12] G. Purna Sudhakar, "A model of critical success factors for software projects," Journal of Enterprise Information Management, vol. 25, no. 6 , pp. $537-558,2012$. DOI= http://dx.doi.org/10.1108/17410391 211272829 .
[13] D. F. Ofori, "Project Management Practices and Critical Success Factors-A Developing Country Perspective," International Journal of Business and Management, vol. 8, no. 21, pp. 14-31, 2013. DOI= http://dx.doi.org/10.5539/ijbm.v8n21p14.

[14] V. Holzmann, and I. Panizel, "Communications management in Scrum projects," in Proceedings of the European Conference on Information Management \& Evaluation. Reading, UK: Academic Conferences and Publishing International Limited, 2013, pp. 67-74.

[15] J. Han, and W. Jung, "How Geographic Distribution Affects Development Organizations: A Survey on Communication between Developers," International Journal of Software Engineering \& Its Applications, vol. 8, no. 6, pp. 241-251, 2014.

[16] T. Niinimäki, A. Piri, C. Lassenius, and M. Paasivaara, "Reflecting the choice and usage of communication tools in global software development projects with media synchronicity theory," Journal of Software: Evolution and Process, vol. 24, no. 6, pp. 677-692, 2012. DOI= http://dx.doi.org/10.1002/smr.566.

[17] B. Sidawi, "Potential use of communications and project management systems in remote construction projects: the case of Saudi Electric Company," Journal of Engineering, Project, and Production Management, vol. 2, no. 1, pp. 14-22, 2012.

[18] K. Tone, M. Skitmore, and J. K. W. Wong, "An investigation of the impact of cross-cultural communication on the management of construction projects in Samoa," Construction Management and Economics, vol. 27, no. 4, pp. 343-361, 2009. DOI= http:// dx.doi.org/10.1080/01446190902748713.

[19] P. Wagstrom, and J. Herbsleb, "Dependency forecasting in the distributed agile organization," Communications of the ACM, vol. 49, no. $10, \quad$ pp. $55-56,2006, \quad \mathrm{DOI}=\mathrm{http} / / /$ dx.doi.org/10.1145/ 1164394.1164420.

[20] M. Monteiro de Carvalho, "An investigation of the role of communication in IT projects," International Journal of Operations \& Production Management, vol. 34, no. 1, pp. 36-64, 2013. DOI= http://dx.doi.org/10.1108/IJOPM-11-2011-0439.

[21] J. Samáková, J. Sujanová, and K. Koltnerová, "Project communication management in industrial enterprises," in European Conference on Information Management and Evaluation, Reading, UK: Academic Conferences International Limited, 2013, pp. 155-163.

[22] K. E. Papke-Shields, C. Beise, and J. Quan, "Do project managers practice what they preach, and does it matter to project success?," International Journal of Project Management, vol. 28, no. 7, pp. 650-662, 2010. DOI= http://dx.doi.org/10.1016/j.jproman. 2009.11.002.

[23] A. M. Pop, I. Pop, and D. D. Dumitrascu, "An Analysis Model Of The Communication Features In Research Project Management," Revista Economica, vol. 65, no. 4, pp. 49-64, 2013.

[24] D. S. Nguyen, "Success Factors for Building and Managing High Performance Global Virtual Teams," International Journal of Sciences: Basic and Applied Research, vol. 9, no. 1, pp. 72-93, 2013.

[25] G. Isern, "Intercultural Project Management for IT: Issues and Challenges," Journal of Intercultural Management, vol. 7, no. 3, pp. 53-67, 2015. DOI= http://dx.doi.org/10.1515/joim-2015-0021.

[26] Project Management Institute, "The high cost of low performance: the essential role of communications," 2013, http://www.pmi.org/ / media/PDF/Business-Solutions/The-High-Cost-Low-PerformanceThe-Essential-Role-of-Communications.ashx, access date: 6.05.2016.

[27] V. E. Pitts, N. A. Wright, and L. C. Harkabus, "Communication in Virtual Teams: The Role of Emotional Intelligence," Journal of Organizational Psychology, vol. 12, no. 3/4, pp. 21-34, 2012.

[28] P. Ziek, and J. D. Anderson, "Communication, dialogue and project management," International Journal of Managing Projects in Business, vol. 8, no. 4, pp. 788-803, 2015. DOI= http://dx.doi.org/10.1108/IJMPB-04-2014-0034.

[29] Oxford Dictionaries. Language matters. $\mathrm{http}: / /$ www.oxforddictionaries.com/definition/english/pattern, access date: 6.05.2016.

[30] J. Rech, R. L. Feldmann, E. Ras, A. Jedlitschka, and B. Decker, „Knowledge Patterns and Knowledge Refactorings for Increasing the Quality of Knowledge," in Knowledge Management, Organizational Memory and Transfer Behavior: Global Approaches and Advancements, 1st ed., M. E. Jennex, Ed., London, UK: IGI Global, 
2008, pp. 281-328. DOI= http://dx.doi.org/10.4018/978-1-60566140-7.ch017.

[31] A. M. Ernst, "Enterprise architecture management patterns," in Proceedings of the 15th Conference on Pattern Languages of Programs, ACM, 2008. DOI= http://doi.acm.org/10.1145/1753196. 1753205.

[32] S. Lukosch, and T. Schümmer, "Groupware development support with technology patterns," International Journal of Human-Computer Studies, vol. 64, no. 7, pp. 599-610, 2006. DOI= http://dx.doi.org/ 10.1016/j.ijhcs.2006.02.006.

[33] E. Gamma, R. Helm, R. Johnson, and J. Vlissides, Design patterns: elements of reusable object-oriented software. Upper Saddle River, NJ: Pearson Education, 1994.

[34] T. Iba, Collaboration patterns: a pattern language for creative collaborations. Japan: CreativeShift Lab, 2014.

[35] N. Schadewitz, „Design patterns for cross-cultural collaboration,” International Journal of Design, vol. 3, no. 3, pp. 37-53, 2009

[36] Y. Verginadis, N. Papageorgiou, D. Apostolou, and G. Mentzas, ,A review of patterns in collaborative work," in Proceedings of the 16th ACM international conference on Supporting Group Work, New York, NY, ACM, 2010, pp. 283-292. DOI= http://dx.doi.org/ $10.1145 / 1880071.1880118$.

[37] K. Muszyńska, "Communication management in project teamspractices and patterns," in Managing Intellectual Capital and Innovation for Sustainable and Inclusive Society, Proceedings of the MakeLearn and TIIM Joint International Conference, V. Dermol, A Trunk, G. Đaković, M. Smrkolj Eds., ToKnowPress, 2015, pp. 1359 1366.
[38] S. Apud, and T. Apud-Martinez, "Effective Internal Communication in Global Organizations," 2008, http://www.iabc.com/ effectiveinternal-communication-in-global-organizations, access date: 6.05.2016.

[39] A. Bilczynska-Wojcik, "Communication management within virtual teams in global projects". Ph.D. dissertation, Dublin Business School, 2014.

[40] J. Douras, "Techniques to Build Respect and Trust with a Remote Workforce," 2010, http://www.iabc.com/techniques-to-build-respectand-trust- with-a-remote-workforce, access date: 6.05.2016.

[41] L. Layman, L. Williams, D. Damian, and H. Bures, "Essential communication practices for Extreme Programming in a global software development team," Information and Software Technology, vo. 48, no. 9, pp. 781-794, 2006. DOI= http://dx.doi.org./ 10.1016/j.infsof.2006.01.004.

[42] F. Y. Y. Ling, S. P. Low, S. Q. Wang, and T. K. Egbelakin, "Foreign firms' strategic and project management practices in china," in Proceedings of Construction Management and Economics: Past, Present and Future. Reading, UK: University of Reading, 2007.

43] S. Modi, P. Abbott, and S. Counsell, "Exploring communication challenges associated with Agile practices in a globally distributed environment," 2012, http://raiseconference.org/wp-content/uploads/ 2012/10/ModiCounsellRAISE-paper-resubmission-final.pdf, access date: 6.05.2016. 